\title{
Geometry and seismic characterization of the subsoil below the Amphitheatrum Flavium, Rome
}

\author{
Ettore Cardarelli ${ }^{1}$, Michele Cercato ${ }^{1,{ }^{*}}$ Luciana Orlando ${ }^{1}$ \\ 1 Sapienza, Università di Roma, DICEA - Area Geofisica, Rome, Italy
}

\author{
Article history \\ Received August 1, 2016; accepted May 10, 2017. \\ Subject classification: \\ Surveys, Measurements and monitoring, Seismic risk, Exploration Geophysics, Magnetic and electrical methods, Seismic methods.
}

\begin{abstract}
The seismic-risk assessment of archeological and monumental sites is extraordinarily challenging from the earthquake engineer's point of view: the monumental structures are generally unconventional and of great value, the geology and ground conditions are often poorly known and the presence of tourists in the area can be massive. In addition, the effects of anthropic and artificial deposits on seismic ground motion are particularly relevant within urban historical sites and should be addressed thoroughly. Under these conditions, non-destructive geophysical methods can be successfully employed to identify key parameters for seismic verification. The main focus of this paper is the application of non-invasive geophysical methods to investigate a famous monumental structure: the Colosseum or Amphiteatrum Flavium (Rome, Italy). Because of the complexity of the subsoil under the Colosseum, a comprehensive 3D approach should be encompassed to fulfil the lack of information still pending on the complex subsoil geometry and characterization, as well on the shape of the monument's foundations. Our investigations are mostly focused on the southern sector of the monument, basically for budget reasons. Despite these limitations, our findings do however contribute to link the reference geologic model to the specific conditions of the anthropic layer and the seismic bedrock at this site, as well as the foundations and the buried parts of the monument below the former arena, providing key input data for the assessment of the response of the Colosseum under dynamic loading.
\end{abstract}

\section{Introduction}

The seismic assessment of archaeological structures is always subjected to a certain degree of uncertainty, depending on the level of knowledge of the building and ground conditions. The interrelation between these two factors is absolutely relevant to define the behaviour of the structure under dynamic loading. Especially for unconventional and monumental build- ings, the soil and the structure (particularly the building foundations) should be examined as a whole system.

The conventional approach for defining the seismic risk of buildings encompasses two main factors:

- the seismic hazard, i.e. the probability that an earthquake with ground motion intensity exceeding a given threshold will occur within a time at the site under investigation. The hazard at the site is the combination of the regional seismicity and the local site effects on earthquake ground motion;

- the seismic vulnerability of the structure, according to its value and exposure.

These problems are generally addressed independently by seismic microzonation studies and modern seismic design. This "uncoupled" approach may not be sufficient under several circumstances especially at archaeological and historical sites, where the role of anthropic deposits on seismic ground response is generally underestimated and invasive methods may not conveniently be applied on large-scale basis in such urban contexts. In fact, seismic microzonation studies are generally focused on the geological evidences, disregarding the disturbance of the geological conditions induced by the construction and the existence of the anthropic fillings below the foundation level.

On the other hand, the level of knowledge on the building foundations is generally limited to the geometry (if schematic drawings are available) or on punctual sampling of materials and direct inspection (trench excavations) which can sample only limited portions of the building.

Although direct inspection and destructive testing is always required in engineering design, little atten- 
tion is generally given to the great diagnostic potential which can be obtained today by high-resolution non-destructive methods. These methods can be conveniently employed to identify key issues for seismic verification (such as ground conditions, foundation type, soil-structure geometry etc.), for complementing the information on material properties, for optimizing the location and for limiting the number of expensive boreholes and excavations [Cardarelli et al. 2007, Cardarelli et al. 2008, Cardarelli and Di Filippo 2009]. The completeness and reliability of the available information is essential to design and optimise any preservation and management project, as different types of analysis and different values of the safety and confidence factors shall be adopted, depending on the quality of the reconstruction of the "current status" of the building.

In this manuscript, we propose the application of non-invasive geophysical investigations oriented to the seismic assessment of a famous monumental structure: the Colosseum or Amphiteatrum Flavium (Rome, Italy). More specifically, we collected borehole-seismic data outside the building and Electrical Resistivity Tomography (ERT) and Ground Penetrating Radar (GPR) inside the monument, below the former arena. The experimental results constitute a necessary link between the geological background of the surroundings and the actual soil structure at this site, which is heavily affected by the properties and geometry of the anthropogenic backfill material. These experimental results should provide the quantitative basis for knowledge-based, strongly-supported input data for the seismic modelling and assessment of behaviour of the Colosseum under dynamic loading.

The geophysical surveys are intended to add fundamental information to the knowledge of the monumental structure, with particular focus on:

- the investigation of the buried part of the structure of the Colosseum, particularly the former arena;

- the investigation of the heterogeneity of the soil beneath the Colosseum, as it is deemed responsible of differential seismic response [Moczo et al. 1995, Funiciello et al. 1995];

- the seismic characterization of the formation in the monumental area: the natural deposits of the Fosso Labicano valley and the anthropogenic materials which are estimated to be thick even more than ten meters, whose site-specific properties are fundamental for defining a realistic seismic response of the structure under dynamic loading. Our investigations are mostly focused on the southern sector of the monument, basically for budget reasons. Despite these limitations, the objective of this study is a general improvement in the knowledge about the buried parts of the monuments and the subsoil, whose complexity clearly requires, in principle, a comprehensive $3 \mathrm{D}$ approach.

\section{Site description and geological background}

The Colosseum is one of the most famous monuments in the World, with over four millions of tourists per year. It is an oval amphitheatre (arena) located in the centre of the city of Rome, Italy. It was designed for gladiatorial contests and public spectacles; the biggest building of its kind, it had four storeys and stood over 45 metres high and measured about $190 \times 160$ metres across. It combined a mix of materials, all of them easily found or produced in the Roman area, including travertine stone (a sedimentary rock made essentially of calcite, deposited by calcium carbonate saturated waters) for the piers and arcades, tuff (softer volcanic rock), but also concrete and bricks for the upper levels and for the ceiling vaults. The emperor Vespasian began its construction in AD 72 but the structure was completed in AD 80 under his successor Titus and later modified by Domitian (81-96 AD). The reigns of these three emperors comprised the Flavian dynasty so that the Colosseum was consequently named as Amphiteatrum Flavium (Flavian Amphitheatre).

Originally, the site chosen for the Colosseum consisted of a low valley of a former tributary of the Tiber River: the Rio Labicano, a stream flowing down the Labicana valley. This valley, located between the Celio and Palatine Hills [Mancini et al. 2014], collected the waters which created a marsh or a lake, depending on the season. The limits of the Labicano valley with respect to the Colosseum are sketched in Figure 1a.

This area was profoundly modified before the construction of the Colosseum. During the times of the Roman Republic the site was reclaimed, with the construction of a drain to discharge the waters towards the Circus Maximus. This area, densely populated with houses and temples at the time, was nearly destroyed after the great fire in $64 \mathrm{AD}$. The emperor Nero used this site to build an enormous palace for himself, called the Domus Aurea (Golden House), which occupied large sections in the centre of the city. In the depression of the former valley Nero built an enormous rectangular pond, surrounded by a portico with columns. Most of the former Domus Area was destroyed by Vespasian, the artificial lake was filled in and the land reused as the location for the new Flavian Amphitheatre, a public building donated by the 

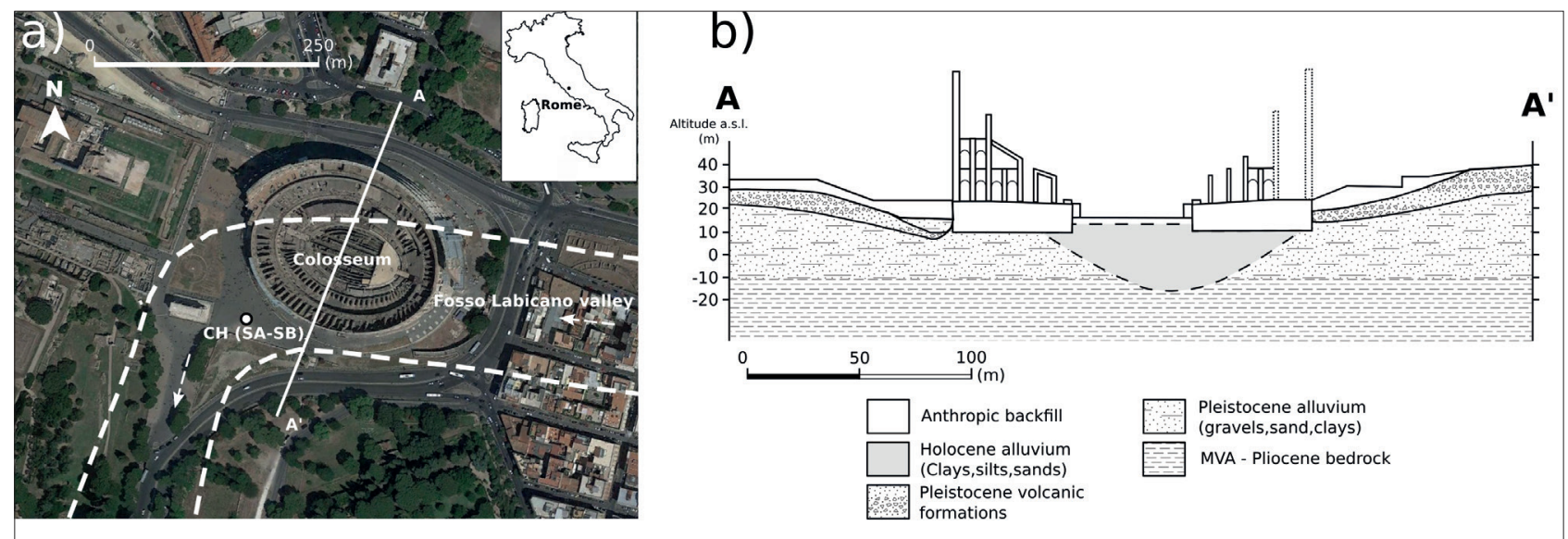

Figure 1. (a) Aeral view of the Colosseum with annoted the limits of the Fosso Labicano Valley and position of the boreholes (SA and $\mathrm{SB})$ employed for crosshole investigations $(\mathrm{CH})$. (b): simplified geological section (A-A') across the Colosseum Area. Figures redrawn after Funiciello et al. [1995] and modified according to Mancini et al. [2014].

emperor to the Roman citizens as the symbol of the new political order.

For these reasons, the site is subjected to specific geological conditions depending on both natural evolution and geological factors as well as artificial intervention.

Galli and Molin [2014] reported 13 historical earthquakes that have exceeded the damage threshold within the Central Archaeological Area (CAA) of Rome. Their analysis covered a time span of approx $2.5 \mathrm{kyr}$, describing the damage induced on monumental buildings by these seismic events. More specifically, two earthquakes that occurred in 443 and 508 (estimated MCS intensity equal or above 7), have certainly produced damages on the Colosseum and the 1703 L'Aquila earthquake (Mw 6.7, epicentral distance 90 $\mathrm{km}$ approx.) induced the collapse of two arches of the monument. Donati et al. [1999] pointed out that the local geological conditions play a major role in defining the seismic response of the CCA of Rome, mainly because of the presence of Holocene alluvial deposits.

The seismic response of the geologic structure beneath the Colosseum was investigated by Moczo et al. [1995]. Their geological model was based on the previous knowledge of the CAA of Rome [Funiciello et al. 1995].

In the CAA of Rome, the geological bedrock consists of marly clay marine sediments (MVA Monte Vatican Unit) which are found about the elevation of the present sea level. In the Colosseum area the Pliocene substratum is lowered by about $10 \mathrm{~m}$ with respect to the surroundings and heterogeneities are recognized below the Colosseum footprint: the northern part is underlaid by an almost horizontal layer of Pleistocene deposits. The southern part overlies a well confined sedimentary valley of a former tributary of the Tiber River [Funiciello et al. 1995, Moczo et al. 1995].

The geometry of the geological model was supported mainly by geological surveys and boreholes, but the dynamic properties of the materials were not the subject at the time of specific in-situ or laboratory studies. The low-stiffness characterization is crucial for seismic risk assessment according to the Italian National building code - NTC08 [2008]. Therefore, in recent years several studies have investigated the low-stiffness properties of the deposits in the CAA of Rome. From a general point of view, for unconventional and historical structures like the Colosseum, the simplified approach suggested by the NTC08 for soil classification is not adequate and specific studies are needed to build a truly representative model of the subsoil and the buried part of the structure.

Bozzano et al. [2000], Bozzano et al. [2008] and Caserta et al. [2012] investigated the different lithotypes constituting the recent sedimentary fill of the Holocene Tiber River Valley under both static and dynamic conditions. Bianchi Fasani et al. [2013] reported the typical ranges of shear-wave velocities observed in situ for the pyroclastic units within Rome city.

More recently, Mancini et al. [2014] and Pagliaroli et al. [2014a] presented a lithotechnical model for seismic zonation and investigated the cyclic properties and soft rocks of the CAA of Rome. In the Colosseum area, the water table is generally around 12 meters above sea level (a.s.l.), see for instance La Vigna et al. [2016] and Pagliaroli et al. [2014b], corresponding to a depth greater than 10 meters below 


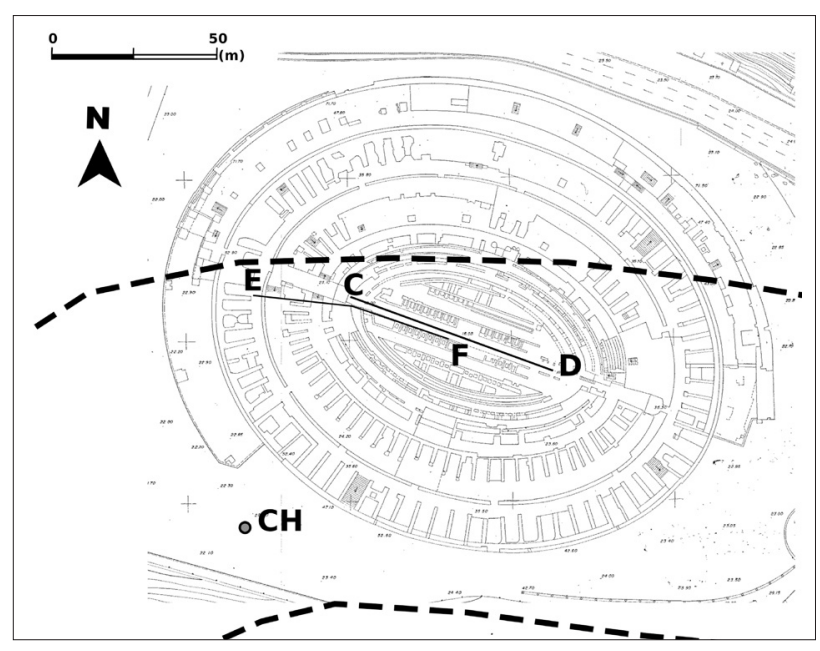

Figure 2. Location of the geophysical investigations: Crosshole $\mathrm{CH}$, ERT lines CD and EF. The black dashed lines represent the limits of the Fosso Labicano Valley as in Figure 1.

ground level (b.g.1.) in the area of interest, whose elevation is generally greater than $22 \mathrm{~m}$ a.s.1. [Funiciello et al. 2008, Funiciello et al. 1995, Mancini et al. 2014].

Moscatelli et al. [2014] mapped the basal surface of the anthropic layer in the CAA of Rome, although the thickness of the anthropogenic deposits could not be mapped in the Colosseum area because a Digital Terrain Model (DTM) was not available as well as the real geometry of the buried foundations and structures of the monument. The basal surface of the anthropic layer was estimated to be ranging between 8 and $20 \mathrm{~m}$ a.s.l. in the Colosseum area, a thickness which in principle can significantly affect the local seismic response.

Pagliaroli et al. [2014b] derived a 2D shear-wave velocity for seismic response analysis along a crossection on the Palatine hill. They assumed a constant value of the geophysical parameters (in particular Shear-wave velocity) for all the litothypes in the CAA with exception of the anthropic layer and the

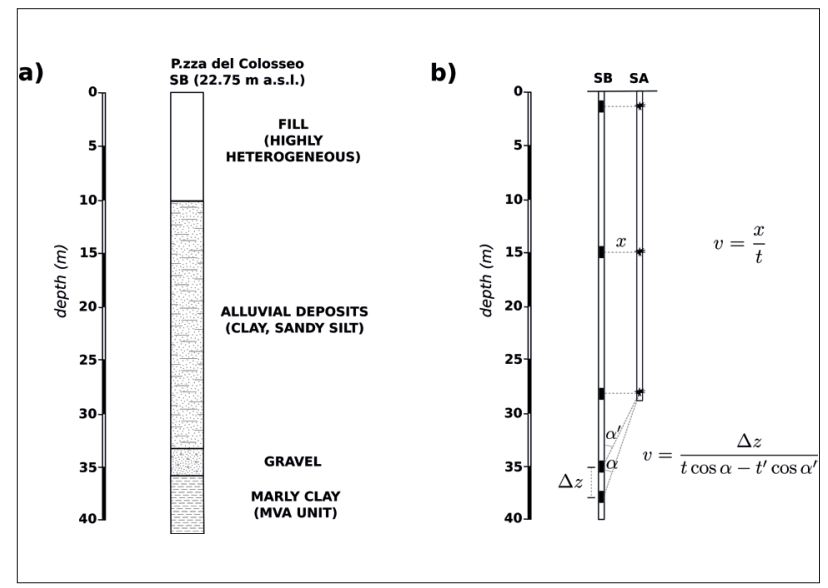

Figure 3. Borehole seismic at the Colosseum. (a) Simplified stratigraphic column of the SB borehole. (b) acquisition geometry of the borehole seismic survey.
MVA Unit, for which a VS gradient with depth was defined, because of either the variability in the CAA or the lack of information at certain depths.

In Figure 1a, we show the site plan of the Colosseum Area with the location of the crosshole survey performed for this study, as well as the recognized geological limits after Mancini et al. [2014]. In Figure $1 \mathrm{~b}$ we report a geological model of a cross section below the Colosseum, integrating the work of Funiciello et al. [1995] and Mancini et al. [2014], to point out the recognized geological heterogeneities below the Colosseum, which are to be further investigated with particular focus on the thickness of the anthropic layer and on the site-specific lowstrain properties in terms of P-wave and shear-wave velocities. The geological section points out the high lateral sediment variation below the foundations of the monument that can provide differential response to the seismic ground motion.

Our investigations are intended to point out the peculiarity of the near surface materials in the Colosseum area, to strengthen the need of a comprehensive study to resolve the unknowns in the characterization of the subsoil around and below the monument. In fact, to model accurately the structure response under dynamic loading there is still lack of information about the structure of the foundation, the geometry of the anthropogenic backfilling and the stiffness of the near surface materials as well as the ones of the seismic bedrock.

\section{Geophysical investigation}

We investigated the Colosseum area employing seismic borehole prospecting, ERT (Electrical Resistivity Tomography) and GPR (Ground Penetrating Radar). The location of the geophysical surveys is reported in Figure 2, while the main aspects of each technique are discussed in the following paragraphs.

\subsection{Borehole seismic}

A borehole seismic survey was performed on a couple of borehole previously drilled in the 90's by INGV (Istituto Nazionale di Geofisica e Vulcanologia) and located in the southern part of the Colosseum (Figure 2). The boreholes are located outside the monument (about $10 \mathrm{~m}$ distant). The borehole stratigraphy (SB) is shown in Figure 3a. The first 10 meters consist of heterogeneous anthropic backfill, overlying Quaternary alluvial deposits. In particular, at $32 \mathrm{~m}$ of depths a few meters of gravel are found, overlying the geologic bedrock, consisting of Pleistocene overconsolidated marly 
clay (MVA). The two boreholes could be inspected up to different depths: the deeper one (SB) was drilled up to $40 \mathrm{~m}$ of depth (b.g.1.), reaching the Pleistocene bedrock (MVA) while the other one could be inspected up to 28.5 meters. For this reason, we adopted a mixed acquisition geometry between crosshole and downhole, as shown in Figure 3. A crosshole survey was performed from the surface to $28 \mathrm{~m}$ of depth moving both the source and the three-component, $28 \mathrm{~Hz}$ borehole geophone at the same depth for each acquisition position. For deeper measures, the source was held fixed at $28 \mathrm{~m}$ of depth and only the borehole geophone was moved in the deeper borehole, resulting in acquisition geometry close to a downhole survey from 28 to $40 \mathrm{~m}$. We employed a borehole sparker as seismic source (see Cercato et al. 2010 for a description of the borehole instrumentation) capable of maximizing the emission of either $\mathrm{P}$ - or $\mathrm{SH}$ - waves using different probe modules. The borehole geophone is equipped with a mechanical clamp to be coupled to the borehole casing. The shear wave can be polarized according to the user's needs and can be controlled using the embedded downhole compass. This source is characterized by high repeatability and an extremely precise (about $10 \mu \mathrm{s}$ ) trigger device, resulting in enhanced stacked coherency which can be particularly useful in noisy urban environments.

The S-wave first arrivals are detected in the recorded seismograms by phase inversion of the polarized S-waves generated by 180 degree rotation of the source.

With reference to Figure 3, for the first part of the survey (up to $28 \mathrm{~m}$ of depth), at each station the seismic velocity $v$ (either the P- and S- wave velocity), is retrieved from the picked travel time $t$ using Equation (1):

$$
v=\frac{x}{t}
$$

On the other hand, the picked travel times in the deeper part of the survey (below $28 \mathrm{~m}$ of depth) are interpreted to provide the vertical interval velocities according to the Equation (2):

$$
v=\frac{\Delta z}{\Delta t_{c}}=\frac{\Delta z}{t \cos \alpha-t^{\prime} \cos \alpha^{\prime}}
$$

Where $t_{c}$ means corrected traveltime, $\Delta z$ is the vertical distance between station, $\alpha$ and $\alpha^{\prime}$ are the angles formed between the vertical and the raypaths under the straight-ray assumption (Figure 3).

The results of the borehole survey are reported in Figure 4, together with the reference stratigraphy of borehole SB.

It is recognized that the anthropic backfilling ma- terial exhibits low elastic properties (shear-wave velocity in the range $150-250 \mathrm{~m} / \mathrm{s}$ ). Analogous values are detected for the upper part of the alluvial deposits (up to about 26 meters of depth), whereas the lower part of the alluvial materials is characterized by a substantial increase in seismic velocities. In particular, the gravelly deposits (32m-36m) exhibit shear-wave velocities up to $730 \mathrm{~m} / \mathrm{s}$, while the velocities are limited to a maximum of $635 \mathrm{~m} / \mathrm{s}$ in the MVA Unit (Pleistocene bedrock). Notably, these values are higher than the $500 \mathrm{~m} / \mathrm{s}$ which have been reported in the surroundings [Pagliaroli et al. 2014a, Bozzano et al. 2008].

\subsection{ERT and GPR}

The location of the two ERT lines performed inside the Colosseum, labeled as CD and EF, is reported in Figure 2. The profiles consisted of 48 electrodes, spaced $1.25 \mathrm{~m}$; apparent resistivity data were acquired using both Wenner-Schlumberger and dipole-dipole configurations to obtain adequate lateral and vertical resolution and good signal strength. We employed $10 \mathrm{~cm} \times 10 \mathrm{~cm}$ flat base copper electrodes [Tsokas et al. 2008] coupled to the soil with conductive gel to perform a totally non-invasive ERT investigation (Figure 5). The injected current range was 50-500 mA.

We used the well-known software $\operatorname{Res} 2 \operatorname{dinv}^{\odot}$ [Loke and Dahlin 2002] for data inversion. For each profile, the two data configurations were merged into a single dataset (3300 measurements) for the inversion. The inverted model of the CD line is displayed in Figure 6 . The final RMS misfit is $6.5 \%$ after five iterations.

The model exhibits large resistivity variations (between 100 and $300 \Omega \cdot \mathrm{m}$ ) in the upper stratum up to about 4 meters of depth. Below this level, the electrical resistivity drops down to $10 \Omega \cdot \mathrm{m}$ and is quite similar till the bottom of the section. The near surface layer is easily recognized as an anthropic stratum below the hypogeum, the subterranean network of tunnels and cages beneath the arena of the Colosseum, which is now exposed. The hypogeum consisted of a two-level subterranean network of tunnels, shafts, mechanical devices and cages, which hosted a large amount of machinery to be operated during the shows and contests. Eighty vertical shafts has been recognized to provide instant access to the arena for all kind of attractions (gladiators, animals, scenery pieces) and the tunnels connected a number of points outside the Colosseum. All the pulley systems needed to operate the wooden mobile structures in the hypogeum probably needed heavy counterweights and hinges, which were probably placed below the walking surface of the hypogeum (which is now the surface on which the 
a)

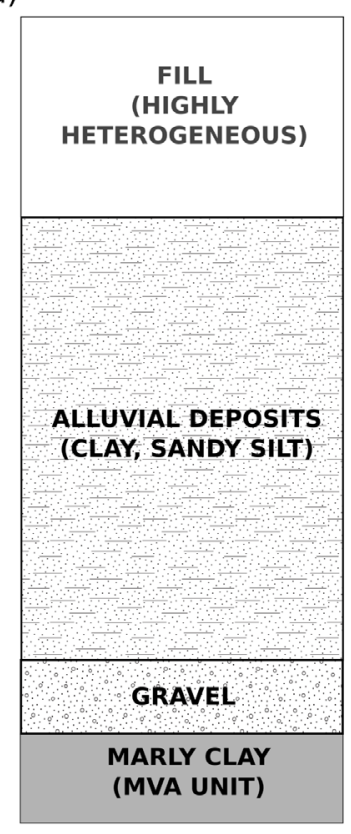

b)

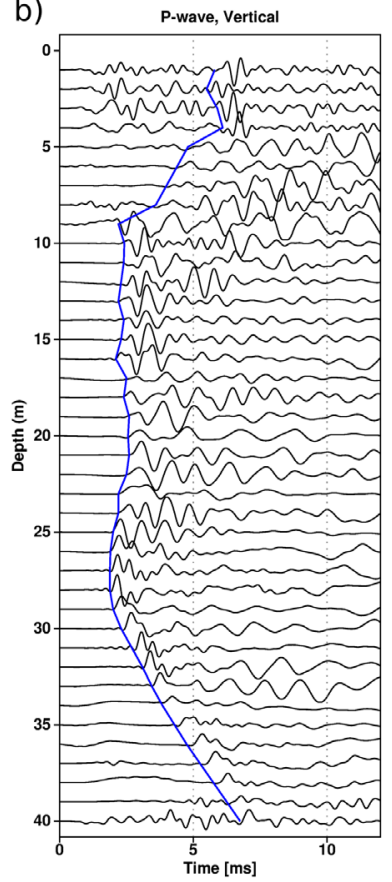

c)

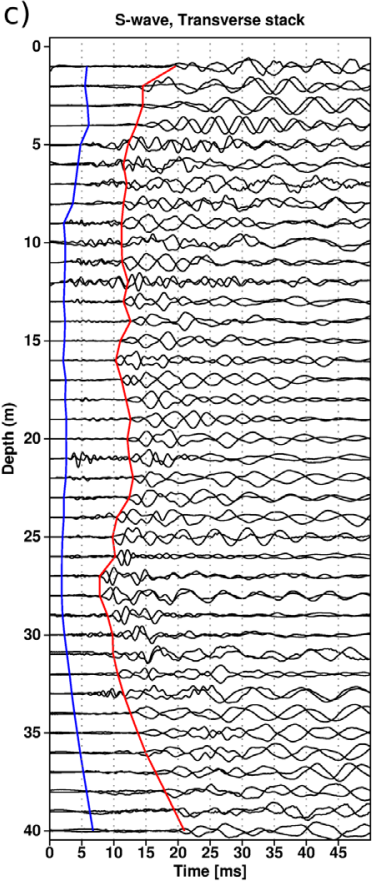

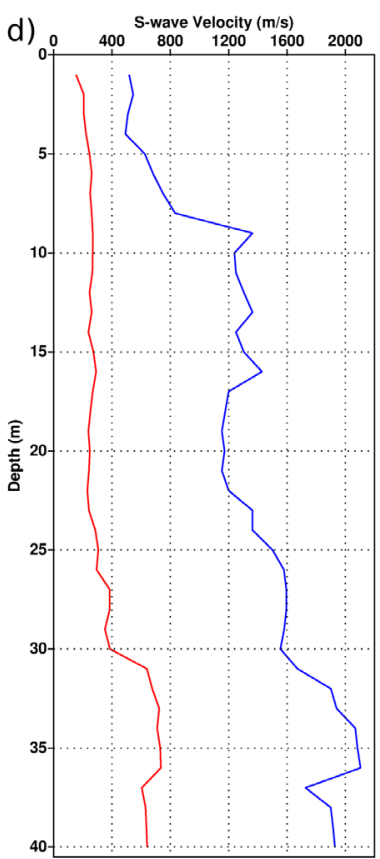

Figure 4. Borehole seismic at the Colosseum. (a) Simplified stratigraphic column of the SB borehole. (b) P-wave records (vertical component): the blue line indicates the first arrivals. (c) S-wave records (transverse component). For each receiver position, the two traces corresponding to the opposite shot directions are superimposed; the red and blue lines show the S-wave and the P-wave arrivals respectively. (d) The P-wave and S-wave velocity profiles.

ERT sections of Figures 6 and 7 were performed). The resistive anomalies in this layer can't be univocally interpreted on the basis of the geophysical evidences only: they could be due to heterogeneous fillings, pre-existing structures or underground utilities.

At depths greater than $5 \mathrm{~m}$, below the anthropic layer, the resistivity values (about $10 \Omega \cdot \mathrm{m}$ ) can be associated to the Holocenic alluvial deposits identified in the borehole stratigraphy as clay and sandy silt. In fact the lower limit of the surface anthropic layer detected with the ERT section at the hypogeum level is consistent with Holocene alluvial deposits detected by borehole drilled about 6 meters above the hy-
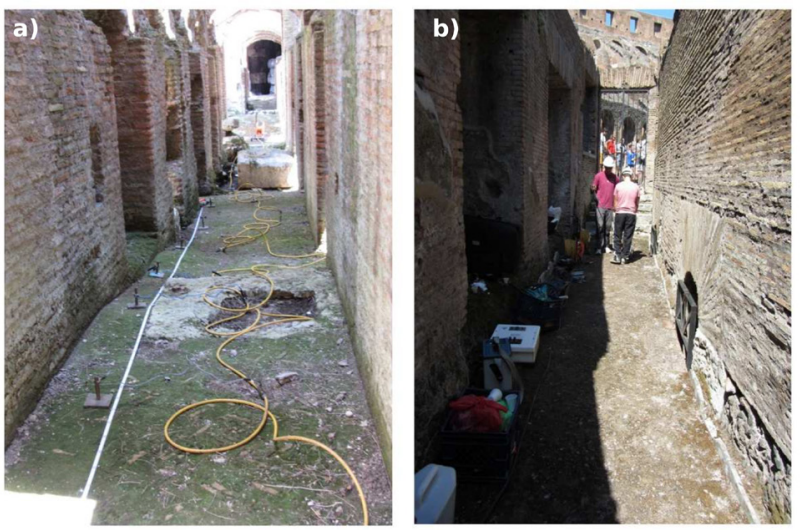

Figure 5. Pictures from data acquisition within the hypogeum. (a) ERT survey employing non-invasive copper electrodes. (b) GPR survey. pogeum. The difference in altitude between the level inside the Colosseum (where the ERT is performed) and the ground surface at the borehole site (Figure $1 b)$ is six meters.

Multi frequency (80, 100, $200 \mathrm{MHz})$ GPR survey was also performed on the CD line. The resulting profile collected with $80 \mathrm{MHz}$ antenna, which better depict the ground, is displayed in Figure 7. The data were processed with a time zero correction, band-pass frequency domain filter (20-300 $\mathrm{MHz}$ ) and an exponential gain. The GPR profile is consistent with the findings obtained by ERT interpretation, showing a highly heterogeneous surface deposits of anthropic origin. Below this layer, the GPR signal has virtually no penetration in the low-resistivity alluvial deposits. This is consistent with the presence of the conductive sediments (10 $\Omega \cdot \mathrm{m}$ ) detected by ERT survey.

The ERT inversion model of profile EF (see Figure 2 for the location) is shown in Figure 8. The slightly curved profile induces error on the inversion model due to the geometric factor of apparent resistivity calculation, which was evaluated to be less than $1-2 \%$, and in the feature of the ground due to the lateral effect of three dimensional structures. The latter error is depth dependent. The profile was inverted as in-line and the final RMS misfit was $8.5 \%$ 


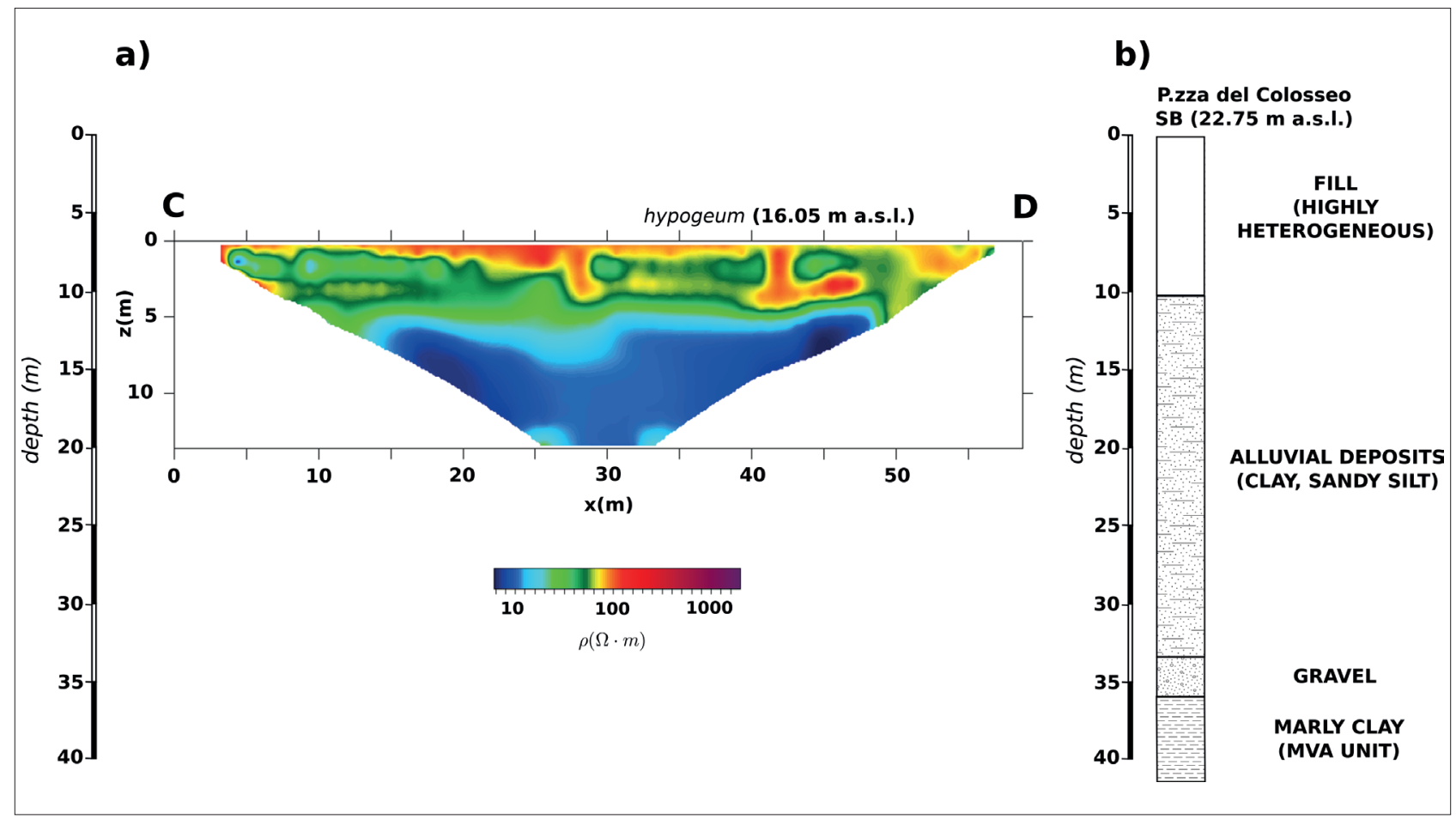

Figure 6. (a) Results of the ERT line CD. (b) Stratigraphy of borehole SB.

after five iterations. Roughly the first half of the EF profile $(0-22 \mathrm{~m})$ is located on the foundations, which appear to be thicker than $10 \mathrm{~m}$ and exhibit values higher than $1000 \Omega \cdot \mathrm{m}$. The foundations show a horizontal discontinuity at about $3 \mathrm{~m}$ of depth, which could be detected at the scale of ERT resolution. The second half of the section $(22-57 \mathrm{~m})$, located in the hypogeum, below the original arena, is consistent with the interpretation described for the ERT section $\mathrm{CD}$ and depicted in Figure 6. This means that the underground structure of Colosseum in the central part (arena) extends, up to a depth of $12 \mathrm{~m}$, the layer (about $10 \Omega \cdot \mathrm{m}$ ) can be associated to the Holocenic alluvial deposits identified in the borehole stratigraphy as clay and sandy silt.

\section{Discussion and conclusions}

The seismic characterization of the formations below the Colosseum i.e. the anthropic backfilling, the Holocene alluvial deposits of the Labicana valley and the Pleistocene Marly Vatican Unit (MVA), will enable more realistic seismic modelling of the soil-structure interaction at the Colosseum site.

We have found that the P-wave velocity ranges from about $500 \mathrm{~m} / \mathrm{s}$ to about $1200 \mathrm{~m} / \mathrm{s}$ in the backfill material, whereas it has values greater than $1200 \mathrm{~m} / \mathrm{s}$ at higher depths, reaching $2100 \mathrm{~m} / \mathrm{s}$ in the gravel and $1800 \mathrm{~m} / \mathrm{s}$ in the MVA unit. The $\mathrm{S}$-wave velocity is quite constant (250-300 m/s) at shallow depths (up to $20 \mathrm{~m}$ ). The gravel exhibits a maximum $S$-wave velocity of approximately $700 \mathrm{~m} / \mathrm{s}$, whereas the maximum shear ve-

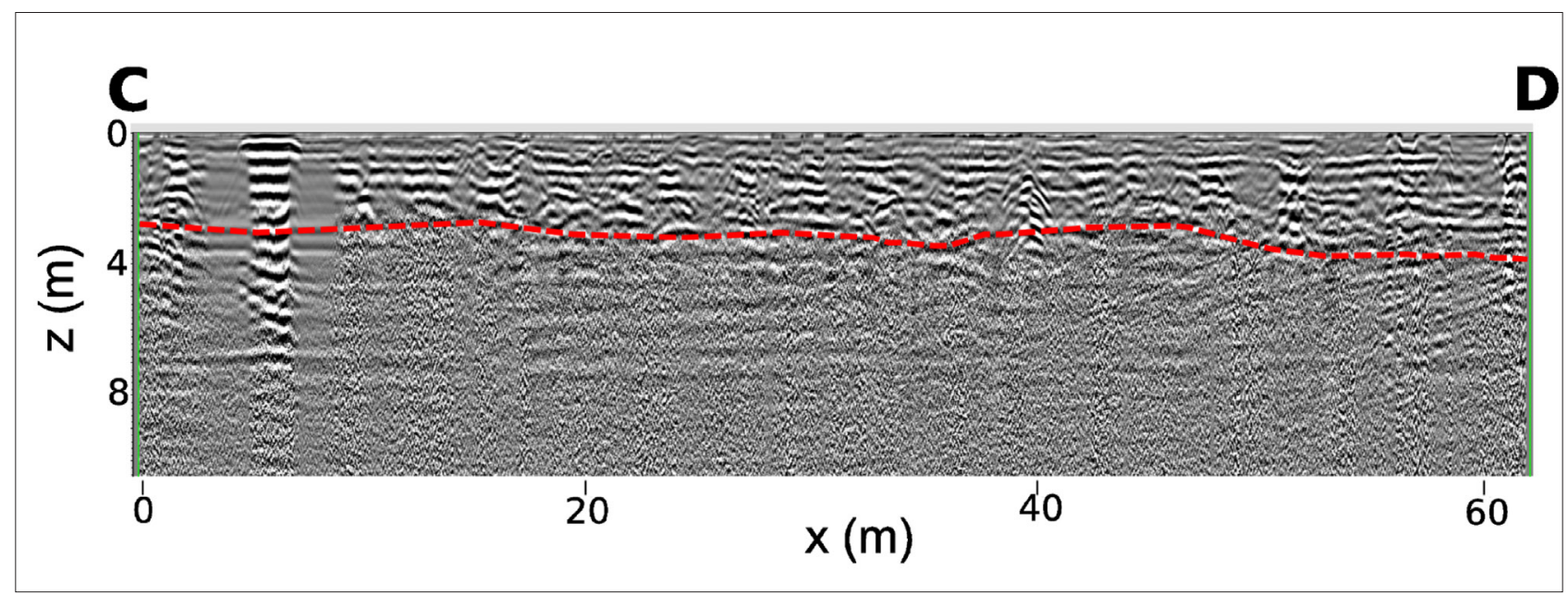

Figure 7. GPR section of line $\mathrm{CD}$ ( $80 \mathrm{MHz}$ antenna). The red dashed lined indicates the limit of the anthropic deposits. 


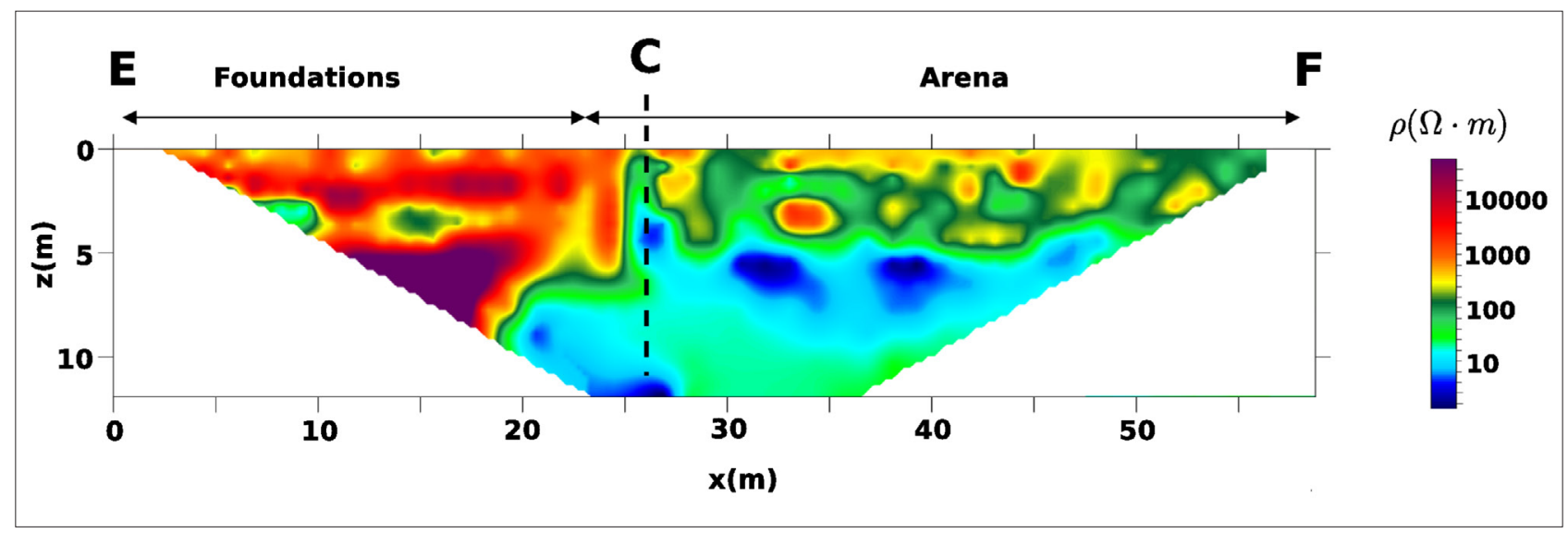

Figure 8. Results of the ERT line EF. The surface is at $16.05 \mathrm{~m}$ a.s.l., which is the elevation of the hypogeum. The dashed line indicates the projection of the starting point $\mathrm{C}$ of the C-D profile (Figures 6 and 7).

locity of the MVA is about $600 \mathrm{~m} / \mathrm{s}$, which is higher than the values retrieved in previous investigations in the surroundings [Bozzano et al. 2008, Pagliaroli et al. 2014a] although not enough to serve as a seismic bedrock at the investigated depth. This is a relevant aspect because the conventional assumption that the MVA Unit exhibits VS velocities less than $500 \mathrm{~m} / \mathrm{s}$ up to hundreds of meters of depth may be misleading in this area.

The ERT and GPR survey pointed out a consistent picture for the geometry below the hypogeum, where a 5-meters thick layer of man-reworked material has been identified. On the other hand, in the outer part of the monument (below the bleachers) the reworked material is at least $10 \mathrm{~m}$ thick.

Regarding the geologic section sketched in Figure $1 \mathrm{~b}$, our lines $\mathrm{CD}$ and EF (Figure 2) inside the arena didn't allowed to extend our investigation outside the Fosso Labicano deposits. The integration between borehole data and surface non-invasive ERT and GPR investigations allowed to define the geometry and the seismic parameters of the main lithological units in the Colosseum area: the results obtained by seismic borehole investigations outside the monument can be directly correlated to the soil geometry obtained by non-invasive geophysical techniques (ERT and GPR) performed on the hypogeum.

Although the extensive study in recent times of the CAA of Rome, our findings suggest that a thorough $3 \mathrm{D}$ approach is still needed to take into account the extreme heterogeneity and peculiar characteristics of the subsoil in the Colosseum area.

\section{References}

Bozzano, F., A. Andreucci, M. Gaeta and R.A. Salucci. A geological model of the buried Tiber River valley beneath the historical centre of Rome (2000). Bull. Eng. Geol. Env., 59, 1-21.
Bozzano, F., A. Caserta, A. Govoni, F. Marra and S. Martino (2008).Static and dynamic characterization of alluvial deposits in the Tiber River Valley: New data for assessing potential ground motion in the City of Rome. J. Geophys. Res., 113, B01303.

Bianchi Fasani., G., F. Bozzano, E. Cardarelli and M. Cercato (2013). Underground cavity investigation within the city of Rome (Italy): A multi-disciplinary approach combining geological and geophysical data. Eng. Geol., 152 109-121..

Cardarelli, E., M. Cercato and G. Di Filippo (2007). Assessing foundation stability and soil-structure interaction through integrated geophysical techniques: a case history in Rome (Italy). Near Surf. Geoph., 5, 141-147.

Cardarelli, E., M. Cercato, R. de Nardis, G. Di Filippo and G. Milana (2008). Geophysical investigations for seismic zonation in municipal areas with complex geology: the case study of Celano, Italy. Soil Dyn. Earthquake Eng., 28, 950-963.

Cardarelli, E. and G. Di Filippo (2009). Integrated geophysical methods for the characterization of an archaeological site (Massenzio Basilica - Roman forum, Rome, Italy). J. Appl. Geoph., 68, 508-521.

Caserta, A, S. Martino, F. Bozzano, A. Govoni and F. Marra. 2012).Dynamic properties of low velocity alluvial deposits influencing seismically-induced shear strains: the Grottaperfetta valley test site (Rome, Italy). Bull. Earthquake Eng.,10, 11331162.

Cercato, M., F. Cara, E. Cardarelli, G. Di Filippo, G. Di Giulio and G. Milana (2010). Shear-wave velocity profiling at sites with high stiffness contrasts: a comparison between invasive and non-invasive methods. Near Surf. Geophys., 8, 75-94.

Donati, S., R. Funiciello and A. Rovelli (1999). Seismic response in archaeological areas: the case-his- 
tories ofRome. J. Appl. Geophysics, 41, 229-239

Funiciello, R., L. Lombardi, F. Marra and M. Parotto (1995). Seismic damage and geological heterogeneity in Rome's Colosseum area: are they related? Ann. Geofis., 38,927-937.

Funiciello, R., A. Praturlon and G. Giordano (2008). La geologia di Roma: dal centro storico alla periferia (in italian). Memorie Descrittive della carta Geologica d'Italia 80, 1-765.

Galli, P. A. C. and D. Molin (2014). Beyond the damage threshold: the historic earthquakes

of Rome. Bull. Earthquake Eng.,12, 1277-1306

La Vigna, F., R. Mazza, M. Amanti, C. Di Salvo, M. Petitta, et al. (2016).Groundwater of Rome. J. of Maps, 12, 88-93.

Loke, M.H. and T. Dahlin (2002). A comparison of the Gauss-Newton and quasi-Newton methods in resistivity imaging inversion. J. App. Geophys, 49, 149-162.

Mancini, M., M. Marini, M. Moscatelli, A. Pagliaroli, F. Stigliano, C. Di Salvo, M. Simionato, G.P. Cavinato and A. Corazza (2014). A physical stratigraphy model for seismic microzonation of the Central Archaeological Area of Rome (Italy). Bull. Earthquake Eng.,12, 1339-1363.

Moczo P., A. Rovelli, P.Labák and L. Malagnini (1995). Seismic response of the geologic structure underlying the Roman Colosseum and a 2-D resonance of a sediment valley. Ann. Geofis., 38, 939-956

Moscatelli, M., S. Piscitelli, S. Piro, F. Stigliano, A. Giocoli, D. Zamuner and F. Marconi (2014). Integrated geological and geophysical investigations to characterize the anthropic layer of the Palatine hill and Roman Forum (Rome, Italy). Bull. Earthquake Eng., 12, 1319-1338.

NTC08 (2008) D.M. 14 gennaio 2008. Norme tecniche per le costruzioni (in Italian). Ministero delle Infrastrutture. Available at http: / / www.cslp.it.

Pagliaroli, A., G. Lanzo, P. Tommasi and V. Di Fiore (2014a). Dynamic characterization of soils and soft rocks of the Central Archeological Area of Rome. Bull. Earthquake Eng.,12, 1365-1381.

Pagliaroli, A., M. Moscatelli, G. Raspa and G. Naso (2014b). Seismic microzonation of the central archaeological area of Rome: results and uncertainties. Bull. Earthquake Eng., 12, 1405-1428.

Tsokas, G. N., P.I. Tsourlos, G. Vargemezis, and M. Novack (2008). Non-destructive electrical resistivity tomography for indoor investigation: the case of Kapnik area Church in Athens. Archaeol. Prospect., 15,47-61.

\footnotetext{
*Corresponding author: Michele Cercato

Sapienza, Università di Roma, DICEA - Area Geofisica, Via Eudossiana 18, Rome, Italy email: michele.cercato@uniroma1.it

2017 by Istituto Nazionale di Geofisica e Vulcanologia. All rights reserved
} 